\title{
FRUTAS EN LA VIDRIERA. LAS EXPOSICIONES AGROINDUSTRIALES Y EL ROL DE LA PRENSA EN MENDOZA (ARGENTINA) COMO ESTRATEGIA DE DIFUSIÓN DE LA PRODUCCIÓN REGIONAL (1920-1928)
}

\author{
FRUTAS NA VITRINE. EXPOSIÇÕES AGROINDUSTRIAIS E PAPEL DA IMPRENSA EM \\ MENDOZA (ARGENTINA) COMO ESTRATÉGIA PARA DISTRIBUIÇÃO REGIONAL DA \\ PRODUÇÃO (1920-1928)
}

FRUITS ON DISPLAY. AGROINDUSTRIAL EXHIBITIONS AND PRESS ROLE IN MENDOZA (ARGENTINE) AS STRATEGY FOR THE REGIONAL DISTRIBUTION OF PRODUCTION (1920-1928)

Florencia Rodríguez Vázquez Instituto de Ciencias Humanas, Sociales y Ambientales (INCIHUSA-CONICET) frodriguezv@mendoza-conicet.gov.ar

\section{Resumen}

Sobre la base de la relación entre ciencia, economía y agroindustrias, el trabajo ofrece un panorama general sobre las exposiciones regionales y conferencias nacionales que se celebraron en la provincia de Mendoza durante la década de 1920. Su importancia radica en que se habrían convertido en un espacio de exhibición y posicionamiento de las producciones regionales más importantes (uvas, frutas, olivos) y en un ámbito de enseñanza y aprendizaje a través de la información actualizada que circulaba entre productores agroindustriales, empresarios y técnicos. La hipótesis de partida plantea que estos encuentros acompañaron la política de diversificación agrícola implementada por el gobierno provincial y se convirtieron en un medio de acceso a técnicas novedosas para los agricultores y productores que no tenían acceso al sistema formal de enseñanza agrícola. En este contexto, se busca también conocer el rol de los periódicos y revistas especializadas como instrumento para dar mayor visibilidad a las problemáticas de las economías en conformación.

Palabras claves: Fruticultura. Exposiciones. Prensa escrita. Mendoza.

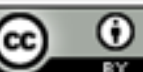

Esta obra está licenciada sob uma Licença Creative Commons 


\title{
Resumo
}

A partir da relação entre ciência, economia e agroindústrias, o trabalho oferece um panorama geral sobre as exposições regionais e conferências nacionais que se celebraram na província de Mendoza durante a década de 1920. Sua importância reside no fato de que ele teria se tornado um espaço para aexposição e posicionamento das mais importantes produções regionais (uvas, frutas, azeitonas) e no âmbito de ensino-aprendizagem através da informação atualizada que circulava entre produtores agroindustriais, empresários e técnicos. A hipótese de partida propõe que estes encontros acompanharam a política de diversificação agrícola implementada pelo governo provincial e se converteram num meio de acessoa técnicas inovadoras para os agricultores e produtores que não tinham acesso ao sistema formal de ensino agrícola. Neste contexto, procura-se também conhecer o papel dos jornais e revistas especializadas.

Palavras-chave: Imprensa escrita. Exposições. Mendoza.

\begin{abstract}
From relations between science, economy and agribusinesses, this paper offers an overview of the regional exhibitions and national conferences which were held in the province of Mendoza during the 1920s. Its importance lies in the fact that it would have become a space for exposure and positioning of the most important regional products (grapes, fruits, olives) and in the context of teaching and learning through updated information circulating between agribusiness producers, entrepreneurs and technicians. The starting hypothesis proposes that these meetings followed the policy of agricultural diversification implemented by the provincial government and became a means of access to innovative techniques for farmers and producers who had no access to the formal system of agricultural education. In this context, it seeks also to know the role of newspapers and specialized magazines.
\end{abstract}

Key words: Press. Expositions. Medoza.

\section{INTRODUCCIÓN}

La relación entre ciencia y economía ha permeado los programas económicos de base agrícola y agropecuaria en Argentina desde fines del siglo XIX, lo cual ha resultado en interés por la historiografía en los últimos años (WEINBERG, 1999; GRACIANO, 2004; GUTIÉRREZ, 2007; CAMPI ET AL, 2011; RODRÍGUEZ VÁZQUEZ, 2012). Estos aportes destacan que los proyectos para estimular la generación y divulgación de conocimientos útiles para las producciones locales y regionales fueron un interés explícito de las dirigencias nacionales desde 1890. Esto se tradujo, en primer lugar, en el diseño y ejecución de programas de formación de recursos humanos que se incorporarían a las agroindustrias regionales, por entonces, en proceso de consolidación. Así desde 1873 -y de manera enfática, a partir de 1896- fue posible verificar la instalación de escuelas agrícolas e industriales en 
puntos estratégicos del territorio argentino. Otro aspecto clave de estos programas fue la contratación de agrónomos extranjeros (europeos y norteamericanos) que se desempeñaron como personal docente y jerárquico en las escuelas, e hicieron estudios precursores sobre las condiciones agroambientales óptimas para la implantación de nuevos cultivos.

En forma simultánea, uno de los mayores era lograr la capacitación y preparación práctica de miles de agricultores que se encontraban dispersos en distintas zonas productivas y que no tenían acceso al sistema formal de enseñanza por motivos de distancia geográfica, económicos y socio-culturales. Por esto, se procuraba ampliar las posibilidades de acceso al conocimiento actualizado y a dinámicas de adaptación e innovación en estos grupos. Estas instancias vendrían a enriquecer y/o complementar los saberes empíricos y experiencias de los productores. En efecto, la concepción evolutiva del cambio tecnológico postula que la generación de conocimientos no corre solo por canales formales sino que es posible detectar la participación de productores realizando ensayos que permitan aumentar la productividad y mejorar la calidad de sus productos.

Como primera repuesta, el Ministerio de Agricultura de la Nación organizó, en 1908, un sistema de agronomías regionales, a través del cual se envió a especialistas a distintas regiones agroproductivas con el objetivo de hacer demostraciones prácticas in situ, ofrecer conferencias y canalizar las inquietudes de los productores. En el caso de Mendoza, esta iniciativa se concretó en 1912 con la contratación del enólogo Enrique Silvetti y se amplió en 1916, con la llegada del coche-escuela provisto por el ferrocarril Buenos Aires al Pacífico.

Sobre esta base, en este trabajo nos interesa conocer y analizar las instancias a través de las cuales los organismos estatales y de la sociedad civil procuraron acercar los conocimientos técnicos novedosos a los agricultores, en espacios que por entonces no estaban asignados a la educación formal. En particular, cobran interés las exposiciones agrícolas como fuente de acceso a información novedosa y espacio de acercamiento y discusión entre los especialistas, empresarios y productores. Para el caso de Mendoza, estos encuentros alcanzaron mayor notoriedad durante la década de 1920 de la mano de los programas de diversificación agroindustrial.

Es necesario señalar que las exposiciones han sido abordadas como eventos que permiten estudiar el reflejo y/o la mirada sobre las imágenes de cada país o grupo organizador forjaron de sí mismos, así como sobre los símbolos y objetos implicados en la construcción de su propia nacionalidad y proyección internacional (DI LISCIA Y LLUCH, 2009, p. 9). Además, constituían un lugar de contacto y sociabilidad entre los mismos productores, 
quienes podían encontrar insumos y tecnología útiles para mejorar sus productos e incorporar procesos más eficientes. Si bien estas oportunidades eran utilizadas por un puñado de empresarios cuya escala y compromiso con la innovación eran mayores y más duraderos que en la generalidad, no puede dejar de admitirse que la participación en eventos de estas características fue aprovechado por un espectro cada vez más amplio y heterogéneo de productores, provenientes de los puntos más distantes (DJENDEREDJIAN, 2009, p. 178).

La organización de estos encuentros, además, estimulaba una fructífera discusión en los medios gráficos acerca de los problemas que afectaban a las principales agroindustrias regionales, ¿cuáles eran las posibilidades del medio local para desarrollar nuevos cultivos?, ¿Cómo el Estado podría fomentarlos?, ¿de que manera podrían organizarse los productores para asegurarse la rentabilidad de sus explotaciones? eran algunos de los interrogantes que se buscaba responder a través de sucesivos escritos. Por ello, el análisis del rol ocupado por la prensa en este proceso resulta complementario del objetivo de trabajo.

Así, sobre la base de antecedentes que analizan la participación de Argentina en las grandes exposiciones internacionales desde mediados del siglo XIX y hasta principios del XX, como una estrategia de promoción internacional de los productos agrícolas e industriales regionales, y a partir de abordajes que comprender la participación en ferias y exposiciones internacionales como una pieza significativa de la innovación tecnológica (DJENDEREDJIAN, 2009, p. 210), estudiaremos qué entidades o dependencias gubernamentales organizaron exposiciones en Mendoza, de carácter local y regional, en el marco de un proyecto agrícola diversificador, vinculando estos encuentros con el contexto social y político.

\section{LA PRODUCCIÓN FRUTÍCOLA DE MENDOZA SE MUESTRA}

La provincia fue representada en diversos torneos internacionales desde fines del siglo XIX, por ejemplo, ocupó un lugar destacado en la Exposición de Filadelfia (1876).

Durante la década de 1880 comienzan a realizarse encuentros similares de carácter público, especializados en los problemas agrícola y ganadero en Buenos Aires, cuya organización, aunque auspiciada por los gobernantes de turno e incluso presidida por éstos, estaba en realidad a cargo de un grupo muy concreto de emprendedores ligados a la innovación tecnológica (DI LISCIA Y LLUCH, 2009, p. 182). La Escuela Nacional de Agricultura, por entonces, el único establecimiento de enseñanza agrícola que funcionaba en 
Mendoza presentó trabajos de algunos de sus alumnos (Boletín Mensual del Departamento Nacional de Agricultura, 1881, p. 369-375).

El gobierno provincial también alentó la participación de los productores en encuentros realizados en otras provincias; en especial, la prensa local ocupó varias páginas instando a los agricultores e industriales locales para que representaran a la producción regional en estos eventos de alcance nacional, e incluso, cuestionaba la reticencia de estos sectores económicos a participar de las exposiciones y ferias. Los órganos de difusión de grupos corporativos también se ocuparon de este tema a partir de la década de 1920, aunque sin hacer referencia a un sector del agro o de la industria en particular.

Sobre la base de estos antecedentes, nos interesa dar cuenta de los eventos que tuvieron a Mendoza como anfitriona.

La primera exposición celebrada en Mendoza data de 1885, organizada por el Club Industrial (Boletín Mensual del Departamento Nacional de Agricultura, 1883, p. 87-88). Recoge, indudablemente, la influencia de las grandes exposiciones de la segunda mitad del siglo XIX y las primeras décadas del XX, “...que pueden pensarse como un conjunto de escenarios en los que los países tenían la oportunidad de proyectar una imagen de acuerdo con una selección de elementos relacionados con los proyectos de nación...”, así como de exaltación del progreso científico occidental (DI LISCIA Y LLUCH, 2009, p. 61). Asimismo, destacamos la influencia de la Exposición organizada por la Unión Industrial Argentina en 1924.

\subsection{ANTECEDENTES, ORÍGENES Y PROPÓSITOS DE LA EXPOSICIÓN DE $1924 / 1925$}

La celebración de exposiciones y conferencias sobre fruticultura durante la década de 1920 no fue casual sino que se relacionó, específicamente, con el interés del Estado, nacional y provincial, en fomentar nuevos cultivos agroindustriales (frutales y olivares). Se esperaba que su difusión y extensión a gran escala funcionara como complemento de la producción vitivinícola, que desde entonces ha liderado la producción agroindustrial pero que durante las primeras décadas de 1920 se vio afectada por crisis cíclicas (1901-1903; 1914-1918; 1922).

Así, en 1912, en la Sociedad Rural Argentina se formó una comisión especial de fomento de la fruticultura y horticultura en el país, atendiendo en especial el estudio de las 
variedades más aptas a difundir, los tipos de embalaje para el traslado de los productos, y las condiciones del mercado de ventas. El empresario vitivinícola Pedro Benegas y el agrónomo francés Paul Pacottet fueron unos de sus integrantes, bajo la presidencia del entonces senador nacional por la provincia de Mendoza, Emilio Civit ${ }^{1}$. Dos años después, el Ministerio de Agricultura de la Nación prestaba atención expresa a la necesidad de extender cultivos distintos a los vitícolas ${ }^{2}$.

Ya en 1918, el proyecto diversificador en la provincia alcanzó mayor atención estatal, probablemente como consecuencia de la segunda crisis vitivinícola que puso en debate público la necesidad inexorable de fomentar nuevos cultivos. Por un lado, se reorganizó la Dirección General de Industrias como Dirección de Fomento Agrícola e Industrial (Boletín Oficial de la Provincia de Mendoza, Dto. 47, 10/4/1918, p. 1.582-1.583), con los objetivos de estimular diversos cultivos agrícolas “...como remedio para las consecuencias desastrosas del monocultivo”, solucionar la crónica superproducción vitivinícola y promover nuevas agroindustrias (aprovechamiento de toda la materia prima). En forma simultánea, verificamos diversas instancias para difundir conocimientos novedosos a gran escala y en espacios institucionales que hasta entonces no se habían vinculado con la enseñanza formal, por ejemplo, se conformó un plantel de técnicos de enseñanza departamental (Registro Oficial de la Provincia de Mendoza, 10-4-1917, p. 153). Finalmente, en febrero de 1922, las reparticiones fundadas en torno al cumplimiento de los mencionados objetivos fueron nucleadas y reinauguradas, nuevamente, como Dirección General de Industrias, bajo la dirección del enólogo italiano Arminio Galanti, quien era un férreo defensor del uso diversificado de la materia prima a través de su aprovechamiento industrial (elaboración de jugo de uva, alcohol vínico y la producción de ácido tartárico) ${ }^{3}$.

En este contexto, y al iniciar la década de 1920, la revista Comercio e Industria, órgano editado en la provincia, en sucesivas editoriales daba cuenta de la importancia de organizar este tipo de encuentros como un medio para difundir las innovaciones productivas entre los agricultores y empresarios que carecían de vías de acceso a información actualizada $^{4}$. El llamamiento de la publicación se fundamentaba en el número creciente de empresarios y productores que comenzaban a interesarse por la diversificación de la agricultura.

\footnotetext{
${ }^{1}$ Boletín del Centro Vitivinícola Nacional, n. 80, mayo de 1912: 2.136-2.137.

${ }^{2}$ Informe presentado al Ministerio de Agricultura por la Comisión asesora de Estaciones Experimentales y Viveros, Buenos Aires, Imp. Pablo Godola, 1914: 7-8.

${ }^{3}$ Insumo indispensable en las bodegas para corregir las deficiencias de acidez de la uva en Mendoza.

${ }^{4}$ Comercio e Industria, abril a junio de 1920, varios números.
} 
En 1922, incluso se convocó a bodegueros mendocinos para participar en la Exposición Internacional de Río de Janeiro. Los trabajos eleccionados para participar en el certamen serían premiados por la Comisión de Fomento Industrial Vitivinícola, dependiente del Ejecutivo provincial. Sin embargo, no hallamos datos de su concreción.

$\mathrm{Al}$ año siguiente, el boletín mensual del BAP se acopló a esta convocatoria, y expresó:

"Lo que el agricultor necesita saber, no es que alguien en alguna parte, por alguna fruta, recibió un premio, sino si sus propias frutas son buenas, si son apropiadas a tal o cual objeto, si existen otras mejores, su transformación industrial y las máquinas necesarias para ello. Y eso solo la exposición local podrá decírselo” (VIDELA, 1923, p. 21).

Es oportuno mencionar que esta publicación, en varias oportunidades, bregó para que este tipo de encuentros fuera de carácter provincial o regional, con el argumento de que solo así tendrían mayor repercusión entre los productores.

Así fue que en 1924 tuvo lugar la Primer Exposición Frutícola de Mendoza, organizada por la Comisión ad hoc -entre quienes de destacaron el agrónomo Carlos Zavalla y el empresario José B. de San Martín-, el Centro Unión del Comercio, Industria y Producción, y el Ferrocarril Buenos Aires al Pacífico (Tabla 1). Al atender a los miembros de la comisión organizadora resulta curiosa la ausencia de importantes empresarios que durante la crisis de 1914 habían iniciado una destacada labor de promoción de la actividad, como Juan Serú, Eduardo Teisaire, Ezequiel Tabanera y Pedro Benegas. Esto podría ser indicio de diferencias o problemas de representatividad en el seno del sector, o bien, de una poco probable desvinculación de estos empresarios de la actividad, sin embargo el origen de esta conflictividad excede el objetivo de estudio de este artículo.

Tabla 1: Provincia de Mendoza. Comisión organizadora de la I Exposición Frutícola, 1924.

\begin{tabular}{|l|l|}
\hline Integrantes & Profesión o puesto que desempeñaba \\
\hline Alejandro Suárez & Vitivinicultor \\
\hline José B. San Martín & Viticultor \\
\hline Pedro Anzorena & Agrónomo \\
\hline Carlos M. Zavalla & $\begin{array}{l}\text { Agrónomo. } \\
\text { Director de la Escuela Nacional de } \\
\text { Vitivinicultura desde 1920 }\end{array}$ \\
\hline Jacinto Anzorena & Ingeniero \\
\hline Francisco Croce & $\begin{array}{l}\text { Agrónomo. } \\
\text { Docente e Investigador de la Escuela } \\
\text { de Vitivinicultura. }\end{array}$ \\
\hline Ricardo Videla & Representante del BAP \\
\hline
\end{tabular}


Fuente: Comercio e Industria, n. 110, 5-3-1924, p. 6-7.

También contó con el respaldo financiero del gobierno provincial y del Ministerio de Agricultura de la Nación (Boletín Oficial de la República Argentina. 27-2-1924, p. 852)

La importancia del encuentro radicó en su doble objetivo, por un lado, como ámbito de enseñanza y aprendizaje de técnicas para cultivar -e industrializar- frutales; y por el otro, demostrar la importancia de la provincia, a escala regional, como una de las principales productoras de fruta ${ }^{6}$. En forma simultánea se proyectaron cintas cinematográficas sobre temas frutícolas (LOS ANDES, 15-2-1924, p. 5). A su vez, contó con la aprobación de la opinión pública, que expresaba días antes de la inauguración: “...el certamen vendrá a poner a la vista de propios y extraños, la selección y exquisita calidad de las frutas de la provincia” (LOS ANDES, 18-1-1924, p. 5).

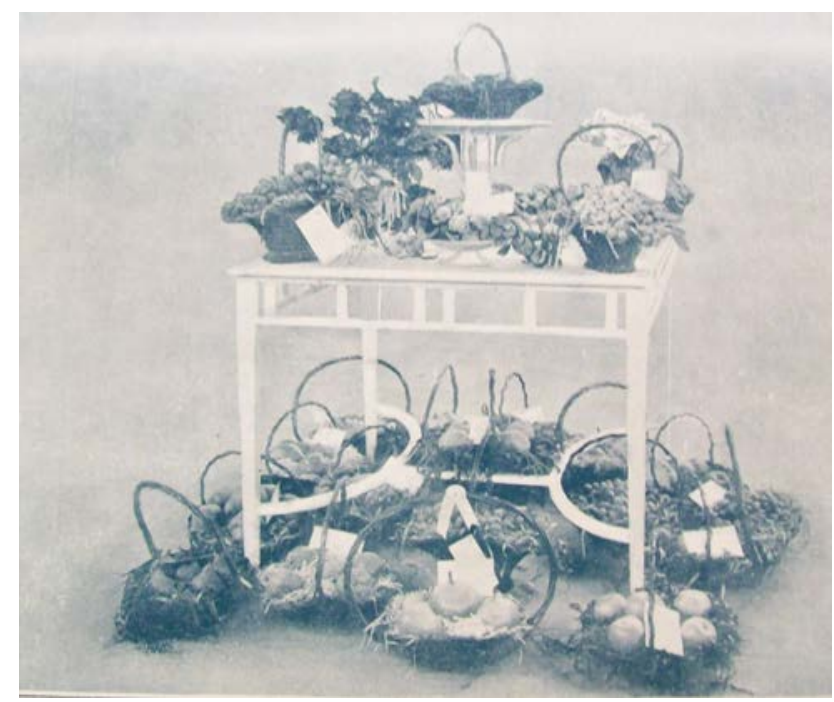

Figura 1: Muestras premiadas en la I Exposición Frutícola de Mendoza, 1924 Fuente: Páginas Argentinas, 1924, s/p.

Las categorías en competición eran: frutas frescas en plato, empacadas, desecadas y elaboradas (conservas y dulces). En esa oportunidad, cobró mayor atención la exhibición de uvas para exportar, probablemente, por una mayor presencia de vitivinicultores interesados en atender a este sector de la economía agrícola y ante los sucesivos envíos experimentales que realizaba el ferrocarril a otras plazasa. También, se le dio especial importancia a la

\footnotetext{
${ }^{5}$ Mensaje del Gobernador de la Provincia de Mendoza Dr. Carlos W. Lencinas leído ante la Asamblea legislativa al inaugurarse el período, 7 de junio de 1924, Mendoza, s/n.

${ }^{6}$ Boletín de la Sociedad Nacional de Agricultura, Chile, 1924, p. 226.
}

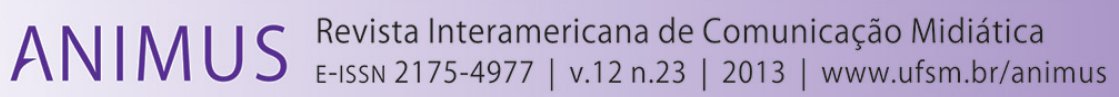


elaboración de jugo de uva, otra arista a través de la cual se intentaba promover y consolidar nuevos cultivos e industrias a escalas local y regional. Esto nos permite confirmar que la organización de este encuentro, al que asistieron productores, empresarios y técnicos -algunos invitados de países limítrofes, como Chile y Uruguay- acompañó el proyecto de diversificación agrícola en la provincia, y funcionó como disparador para poner en el centro de la atención pública las demandas e intereses de un sector que buscaba consolidarse en el abanico de la economía provincial. En efecto, los productos exhibidos y, en especial, aquellos premiados eran la prueba más fidedigna de la concreción de los proyectos agrícolas sobre diversificación y daban cuenta del estado del porvenir de este sector. Las imágenes reproducidas en diversas revistas y álbumes son el testimonio de la cristalización de este proceso.

Notamos, por último, la convergencia de especialistas de larga trayectoria académica en la provincia, junto con empresarios vitivinícolas interesados en diversificar sus emprendimientos, y representantes del ferrocarril Buenos Aires al Pacífico (Tabla 1). La asistencia de este agente fue clave en tanto que la empresa durante la década de 1920 se interesó especialmente en la promoción de cultivos frutícolas y con este objeto inició una consistente labor de experimentación y divulgación. La revista mensual editada por la empresa promovió este proceso de circulación de información y alentó especialmente la participación de los productores y comerciantes en la I Exposición. El fundamento de estas iniciativas residía en que iba a ser el ferrocarril el medio para trasladar las producciones agrícolas hasta el mercado de consumo ubicado en el Litoral argentino.

- Fruticultores! Si poseéis frutas de valor comercial, mandadlas a la Exposición Frutícola: habrá premios para las mejores.

- Comerciantes! Exhibid en la Exposición Frutícola vuestras maquinarias, implementos, aparatos o productos para fruticultura. Será la mejor oportunidad de hacerlos conocer. Solicitad espacio con tiempo.

- Elaboradores de frutas secas. En la exposición frutícola habrán secciones especiales y premios para frutas en dulce y secas, la industria del porvenir!

Fuente: Revista Mensual del BAP, n. 75, febrero de 1924, p. 49 


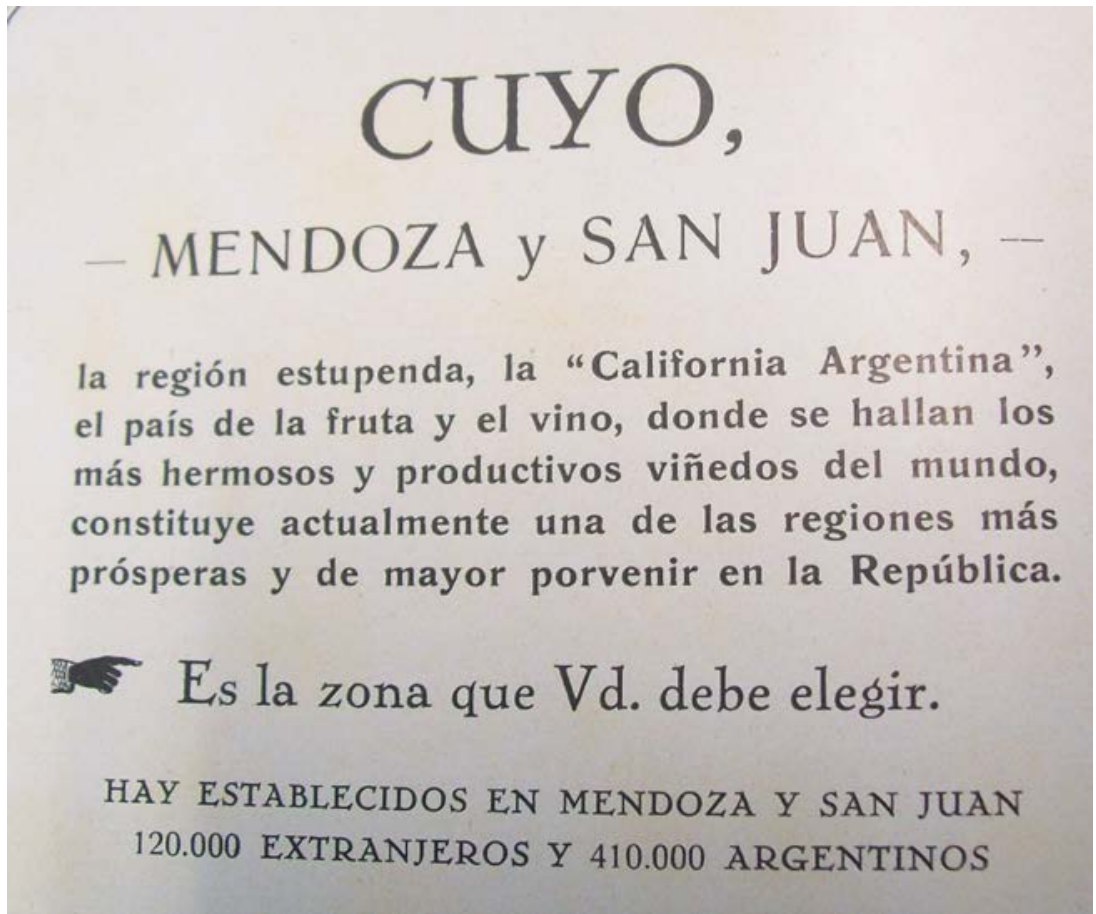

Figura 2: Publicidad sobre colonización y fruticultura en Mendoza Fuente: Videla (1923)

\subsection{EL VALOR AGREGADO DE LA EXPOSICIÓN}

Los resultados favorables de este tipo de encuentros pueden evaluarse desde diversos enfoques.

Por un lado, con respecto a su contribución al aprendizaje técnico de los productores. La exhibición y publicidad de productos, algunos en etapa experimentación, constituyó una fuente de actualización para los asistentes, quienes al aplicar o adaptar las nuevas técnicas en cada explotación, habrían servido de modelo para los productores más cercanos.

$\mathrm{Al}$ respecto enfatizaba una publicación especializada:

Es allí donde el agricultor tiene oportunidad de ver con sus propios ojos los adelantos alcanzados en el mejoramiento de los productos que le interesan... puede comparar mejor sus propios resultados con los de otros agricultores y 
derivar de ello lecciones útiles para el futuro. (Revista Mensual BAP, febrero de 1924, p. 47)

Por otro lado, los preparativos para la exposición aportaron el clima ideal para que la prensa local atendiera específicamente los problemas que afectaban a este sector de la economía, entre ellos, el mejoramiento de las condiciones de comercialización de la producción, la necesidad de un transporte “adecuado y económico” (Los Andes, 11-1-1924: 5; 17-2-1924: 5) parar trasladar las frutas hasta el mercado de ventas. Para el periódico este era un problema prioritario a resolver, incluso antes que la difusión de técnicas para garantizar la óptima calidad de los frutos:

Hay zonas frutícolas en la provincia, como la de San Rafael, en donde la mayor parte de su excelente producción se pierde todos los años por no ser posible el negocio de su exportación a causa de lo elevado de los fletes y de lo inadecuado de los transportes. Y esto no se contrarresta ni se subsana con exposiciones, sino con la reforma en los medio de conducción y con el abaratamiento racional de las tarifas. (Los Andes, 25-1-1924, p. 5).

Es decir, que aún dadas las condiciones agroambientales óptimas para una producción de calidad que satisficiera las demandas de los consumidores, el periódico consideraba que las tarifas del transporte aparecían como un obstáculo para la consolidación de la fruticultura. Este problema transitó toda la etapa de estudio, y fueron recurrentes los reclamos para la disminución de los costos así como también, con posterioridad, de que el ferrocarril proveyera de los vagones adecuados para que las frutas llegaran en buen estado al mercado de consumo.

Por último, cabe destacar que la repercusión de este encuentro fue significativa. Ese mismo año, la Sociedad Nacional de Agricultura de Chile instaba al gobierno para que realizara en el país una reunión con similares características: "Esperamos que el Gobierno chileno debidamente penetrado el inmenso poder educativo de estos torneos, ayude pecuniariamente a la realización periódica de estas exposiciones en nuestro país, como un medio de fomentar la industria frutícola...”. 7

\section{LA FRUTICULTURA, OBJETO DE DEBATE NACIONAL}

Al promediar la década de 1920 los encuentros especializados adquirieron mayor envergadura a escalas nacional y provincial, pero se buscando nuclear a especialistas que

\footnotetext{
${ }^{7}$ Informe presentado por Ing. Agr. Bisquert. Boletín Sociedad Nacional de Agricultura, Chile, 1924, p. 233. Fuente facilitada por el Dr. Claudio Robles Ortiz.
} 
debatieran aspectos técnicos de la actividad. Así en 1926 y 1927 se organizaron conferencias, bajo la concepción de que el contacto de los agricultores -rudimentarios, prácticos, no expertos- con los agrónomos -hombres de ciencia- redundaría en un progreso notable para las explotaciones agrícolas ${ }^{8}$. En uno de los discursos inaugurales se planteó que la orientación de la comercialización frutícola era el principal punto a resolver.

La periodicidad de estos encuentros fue inusitada, y habría que esperar más de una década para la celebración de la IV Conferencia, que tuvo lugar en Río Negro. La sede de estas reuniones no es azarosa sino que demuestra el interés dado en cada economía regional en la promoción de la fruticultura, ya fuera como cultivo central o accesorio.

La importancia de estas reuniones se verificó, además, en un proyecto de ley presentado en 1927 en el cual se establecía la obligatoriedad de celebrar exposiciones cada tres años, como una manera de fomentar la fruticultura ${ }^{9}$.

La provincia de Córdoba fue sede de las I y II Conferencia Nacional de Fruticultura. Una de las conclusiones de esta última, en 1927, fue el nombramiento de subcomisiones para el estudio de la fruticultura en distintas regiones del país, para tal finalidad los agrónomos Mario Estrada (BAP), Santiago Soler (Gobierno de Mendoza, Francisco Croce y Ernesto Riveros (ambos agrónomos mendocinos perfeccionados en el extranjero) fueron comisionados para realizar el estudio en la Región Andina ${ }^{10}$. También, se formó la Sociedad Nacional de Fruticultura, bajo la presidencia del Ing. Emeterio Tarragó, como una moción de la Comisión de Cultivos Frutales, coordinada por Santiago Soler, delegado de Mendoza. La finalidad de esta asociación era "fomentar el adelanto de la fruticultura en sus fases técnica y comercial, y vincular a las personas e instituciones que desarrollen sus actividades en la investigación, la producción, la industria y el comercio frutícolas”. Prontamente ejerció influencia a escala local, pues en 1928 se formaron dos asociaciones similares que nuclearon a los productores frutícolas del Sur y Oeste (Valle de Uco) provincial.

Ese mismo año, Mendoza fue sede de la III Conferencia Nacional de Fruticultura y I Internacional, bajo la organización del gobierno de turno, por entonces, bajo el liderazgo del bodeguero lencinista Alejandro Orfila. Así, la organización de estos encuentros pasó de manos de entidades sectoriales a la responsabilidad del estado provincial. La comisión organizadora estuvo integrada por técnicos con importante trayectoria en la administración pública provincial, y en caso de Soler y Anzorena, con amplia experiencia en la organización

\footnotetext{
${ }^{8}$ Discurso del delegado de la Dirección General de Enseñanza Agrícola del Ministerio de Agricultura ingeniero agrónomo Raúl Battilana Bollini. I Conferencia Nacional de Fruticultura, Córdoba, 1926, p. 17.

${ }^{9}$ Corporación Frutícola Argentina. Proyecto de ley de Santiago Soler, 1928, p. 105.

${ }^{10}$ Gobierno de Córdoba, II Conferencia Nacional de Fruticultura, Córdoba, 1926, p. 27.
} 
de este tipo de eventos. A su vez, fueron convocados algunos empresarios representativos del sector, como mostramos a continuación, que si bien no eran funcionarios estatales sí gozaban de cierta legitimidad en la sociedad.

Tabla 2: Provincia de Mendoza. Comisión Organizadora de la III Conferencia Nacional de Fruticultura y I Internacional

\begin{tabular}{|l|l|}
\hline Integrantes & Profesión o puesto que desempeñaba \\
\hline Santiago Soler & Director de Chacras Experimentales \\
\hline Pedro Anzorena & $\begin{array}{l}\text { Agrónomo regional en la Ciudad de } \\
\text { Mendoza }\end{array}$ \\
\hline Leopoldo Suárez & Enólogo. Senador Provincial \\
\hline José Raúl Ponce & $\begin{array}{l}\text { Agrónomo. Director de la Escuela } \\
\text { Nacional de Vitivinicultura desde 1920 }\end{array}$ \\
\hline Pedro Benegas & $\begin{array}{l}\text { Empresario bodeguero y frutícola. Godoy } \\
\text { Cruz. }\end{array}$ \\
\hline Luis Tirasso (h) & Vitivinicultor. Guaymallén. \\
\hline Victor Denis & Empresario frutícola. San Rafael. \\
\hline
\end{tabular}

Fuente: Boletín Oficial de la Provincia de Mendoza, 18-8-1927, p.

En esa oportunidad, las comisiones de trabajo (Tabla 3) que se mantuvieron fueron las que abordaron los tópicos cultivo de frutales y viticultura. Este última se debía, sin duda, a que la provincia era el núcleo productivo de la región. La forma de combatir las plagas más comunes también ocupó un lugar importante. Lo mismo ocurrió con las temáticas en torno al traslado y comercialización del producto, concentrando uno de los puntos más álgidos debido a que comprometía no solo a la cuestión de las tarifas de traslado sino también a la acción de los ferrocarriles en torno a la provisión de vagones frigoríficos adecuados que garantizaran el óptimo estado de la producción a destino. También fue recurrente el problema de la comercialización de los productos en los puntos de ventas. Para los agrónomos, una de las formas de sortear este obstáculo fue la formación de cooperativas de producción y venta en diferentes puntos de Argentina; para lo cual se consideraba determinante el apoyo gubernamental. La vigencia de este tema cristalizó en la formación de una comisión especial para su discusión.

El discurso inaugural de la Tercera Conferencia recuperó especialmente estos tópicos estableciendo una correlación entre la organización comercial de los productores y la prosperidad de la fruticultura (CORPORACIÓN FRUTÍCOLA ARGENTINA, Sesión 
inaugural, 29 de abril al 7 de mayo de 1928, p. 15). En particular, Santiago Soler -quien por entonces gozaba de cierta notoriedad pues era director de Chacras Experimentales ${ }^{11}$ - expuso sobre el fomento frutícola en Mendoza durante 1927; asimismo, solicitó especial atención para el sostenimiento de las chacras experimentales y la sanción de una ley de fomento frutícola (LOS ANDES, 3-5-1928, p. 3).

En suma, la importancia de este encuentro radicó en que se pusieron en debate los principales problemas y desafíos para una agroindustria aún en vías de consolidación, así como también, en que se solicitó la sanción de normas e indicaciones para el mejoramiento de las explotaciones; también, se trataron los aspectos técnicos de la fruticultura desde el cultivo hasta la comercialización, en los mercados interno y externo (Revista de Agricultura, Industria y Comercio, n. 273, mayo 1928)

Tabla 3: Provincia de Córdoba y Mendoza. Comisiones de trabajo en las conferencias nacionales de fruticultura (1925-1928)

\begin{tabular}{|c|c|c|c|}
\hline $\begin{array}{c}\text { Lugar y año } \\
\text { de la reunión }\end{array}$ & $\begin{array}{c}\text { CÓRDOBA. } \\
1926 \\
\end{array}$ & $\begin{array}{c}\text { CÓRDOBA. } \\
1927 \\
\end{array}$ & $\begin{array}{c}\text { MENDOZA. } \\
1928 \\
\end{array}$ \\
\hline \multirow{8}{*}{$\begin{array}{l}\text { Comisiones } \\
\text { de trabajo }\end{array}$} & \multicolumn{3}{|c|}{ Cultivos frutícolas } \\
\hline & - & \multicolumn{2}{|c|}{ Viticultura } \\
\hline & $\begin{array}{l}\text { Enfermedades y } \\
\text { plagas de los } \\
\text { vegetales }\end{array}$ & $\begin{array}{c}\text { Plagas y } \\
\text { enfermedades }\end{array}$ & $\begin{array}{l}\text { Plagas y enfermedades de } \\
\text { los frutales. Climatología }\end{array}$ \\
\hline & - & - & $\begin{array}{c}\text { Irrigación, Saneamiento y } \\
\text { Mecánica Agrícola }\end{array}$ \\
\hline & Industria de la fruta & $\begin{array}{c}\text { Industrias } \\
\text { (fabricación de } \\
\text { dulces y } \\
\text { conservas) }\end{array}$ & \multirow[t]{2}{*}{$\begin{array}{l}\text { Industria, transporte y } \\
\text { comercio }\end{array}$} \\
\hline & \multicolumn{2}{|c|}{ Transporte y comercio } & \\
\hline & - & $\begin{array}{c}\text { Cultivos } \\
\text { subtropicales }\end{array}$ & $\begin{array}{c}\text { Clasificación pomológica y } \\
\text { viveros }\end{array}$ \\
\hline & Fomento frutícola & - & $\begin{array}{l}\text { Cooperación, fomento } \\
\text { frutícola, legislación y } \\
\text { prensa }\end{array}$ \\
\hline
\end{tabular}

Fuente: Elaboración propia sobre la base de Gobierno de la Provincia de Córdoba, Primera Conferencia Nacional de Fruticultura, 1926: 8-9; Segunda Conferencia Nacional de Fruticultura, 1927; Corporación Frutícola Argentina. Reglamento Interno. 1928, p.6.

\footnotetext{
11 Esta repartición fue fundada en 1926 con los objetivos de buscar nuevas orientaciones a las actividades agrícolas y estimular la orientación práctica de la agricultura y la guía eficaz para el mejor aprovechamiento de los factores naturales en la Provincia. Su organizó complementó la política de diversificación agrícola en Mendoza
} 
Con motivo de este encuentro, una vez más los diarios locales y también las revistas de circulación nacional (Revista de Agricultura, Industria y Comercio, Nuestra Tierra, entre otras) ${ }^{12}$ se hicieron eco de las problemáticas del sector. Por ejemplo, la revista mensual del Centro Vitivinícola Nacional promovía el consumo de frutas. Desde los diversos escritos, registramos las estrategias propuestas por los agrónomos: el abaratamiento del producto y, una vez más, la organización de las ventas en cooperativas para evitar las maniobras especuladoras. Con esto, destacamos que los especialistas no solo atendían a la faz netamente técnica de la producción sino también a los aspectos comerciales, publicitarios, hábitos de consumo, entre otros. A modo de ejemplo, manifestaba Ernesto Riveros, técnico del Ministerio de Agricultura de la Nación:

"el productor entrega [la fruta]a precios muchas veces de ruina a los intermediarios quienes suplen la falta de organización de los productores. Y cuando éstos han deseado vender directa y personalmente su fruta al consumidor, han ido a la ruina por falta de experiencia y por malos resultados económicos obtenidos en la venta” (Revista de Agricultura, Industria y Comercio, marzo de 1928, n. 271, p. 141).

Esto permite confirmar que ante los problemas de organización comercial y de ventas de las frutas -denunciados por la prensa local en diversas oportunidades- el grupo de los especialistas apostaba a la organización cooperativa como la forma primordial para resolverlos. Así se desprende de la continuidad temática de los diversos escritos consultados, cuyas propuestas estarían validadas por el grado de legitimidad de este grupo entre sus pares.

Además, es importante destacar que estos artículos -algunos de ellos con un fuerte componente técnico- eran acompañados por frases ilustrativas sobre las ventajas del consumo de frutas: "La naranja da energías” "La fruta no se debe guardar con llave. Si desaparece de la alhacena, se compra más” “La fruta puede comerse a cualquier hora del día. Nunca hace daño. No ahorre en frutas” “¿Qué la fruta es cara?! Mucho más cuestan los médicos y cirujanos” (Nuestra Tierra, n. 169, mayo de 1928, varias páginas). Ya en la década de 1930 las estrategias para promover el consumo de distintos productos nacionales (frutas, vinos, yerba) adquirieron un matiz sistemático (Girbal-Blacha y Ospital, 2005; Ospital, 2013).

El mismo órgano, en un editorial de mayo, apelaba a los organismos gubernamentales, y en particular, al Ministerio de Agricultura de la Nación a dar curso a las propuestas emanadas de la III Conferencia Nacional de Fruticultura (Revista de Agricultura, Industria y

\footnotetext{
${ }^{12}$ La primera se editaba desde 1905, y era el órgano de expresión de los empresarios vitivinícolas más poderosos nucleados en torno al Centro Vitivinícola Nacional; en tanto que Nuestra Tierra era presentada como "la revista de la estancia, de la granja y el hogar” bajo la dirección del agrónomo Mario Estrada. Se abocaba a la difusión de artículos técnicos y novedades sobre agricultura en general.
} 
Comercio, n. 773, mayo de 1928, s/p). Con esto confirmamos que estos encuentros eran una forma clara de visibilizar las posibilidades y problemas de este sector agroindustrial y lograr la atención de las autoridades. Francisco Croce, agrónomo del gobierno mendocino y docente -es decir, una voz con respaldo científico el tema-, también se refería a los problemas de la fruticultura mendocina en el Boletín Mensual del BAP.

Por otro lado, en diversas oportunidades los agrónomos ya habían cuestionado la falta de fomento público a la producción frutícola (Revista de Agricultura, Industria y Comercio, n. 258, febrero de 1927, p. 87). Un editorial titulado "La hora de fruta” manifestaba que los delegados reunidos en Córdoba "se han propuesto formar un frente único para el progreso de la fruticultura, porque desconfían de la acción de fomento del gobierno nacional” (Nuestra Tierra, n. 156, abril de 1927, p.). En este contexto, fueron constantes las referencias sobre la necesidad de una impulsar una política proteccionista de la producción nacional (Revista de Agricultura, Industria y Comercio, n. 260, abril de 1927, p. 207) como se sugirió luego de la II Conferencia Nacional de Fruticultura de Córdoba. En efecto, la competencia de la producción extranjera era concebida como un obstáculo para la consolidación de las agroindustrias nacionales.

Sin embargo resultaría importante matizar estas apreciaciones pues ya hemos detectado diversas medidas del Ejecutivo provincial para promover el cultivo de frutales y su posterior industrialización desde 1908. Cabría preguntarse, entonces, en futuros trabajos sobre la repercusión de estas políticas sectoriales y en caso de que hubiera sido escasa, profundizar en los motivos de la baja adhesión por parte de los posibles beneficiarios.

\section{REFLEXIONES FINALES}

La celebración de exhibiciones y conferencias sobre fruticultura adquirió un matiz significativo al promediar la década de 1920 en Mendoza. Entidades sectoriales, primero, y luego el Ejecutivo Provincial se abocaron a la organización de estos encuentros que tuvieron varias motivaciones. Por un lado, promocionar el cultivo de frutales y sus derivados; por el otro, crear espacios específicos de discusión de los problemas técnicos, comerciales y económicos que afectaban al sector. Así, se estimuló un importante proceso de circulación de información entre productores, empresarios y técnicos, colectivos que por lo general carecía de instancias de participación complementaria. En particular, las exposiciones, ferias y muestras son los espacios donde se han articulado con mayor asiduidad estos actores, para 
competir por sus producciones más óptimas, de manera, que fueron ideados como un punto de exhibición pero también de difusión de técnicas novedosas. El valor añadido de esta dinámica reside en que era probable que los asistentes buscaran imitar el caso exitoso particular. (efecto demostración), por lo cual, en este sentido, cumplieron un rol de enseñanza no formal.

Si bien en Mendoza se registró solo una exposición sobre fruticultura en el período de análisis, su organización funcionó como disparador para interesar a los actores en la participación en eventos similares en otras provincias y países; y para estimular la extensión de los cultivos frutales y la incorporación de técnicas de avanzada.

En tanto que las Conferencias Nacionales de Fruticultura se erigieron como una instancia privilegiada para la confrontación de ideas sobre los rumbos a dar a los proyectos económicos regionales, por lo que habrían servido de fundamento técnico para el diseño de posteriores políticas públicas sectoriales. Estas conferencias -pensadas con una dinámica similar a lo que hoy se conoce como jornadas o congreso- nucleaban a los agrónomos y especialistas sobre la materia para discutir los aspectos técnicos y económicos de la actividad, así como también, el rumbo que debía adoptar en los espacios regionales.

Por su parte, el valor agregado de estas reuniones estuvo dado porque se logró visibilizar de manera contundente los problemas del sector en los medios gráficos, provinciales y nacionales. Así, para la década de 1920 contamos con las apreciaciones de la prensa escrita y revistas sobre fruticultura e industrias anexas de circulación nacional (Agricultura, Industria y Comercio, Nuestra Tierra, Agronomía, Revista Mensual del BAP) y otras editadas en Mendoza (Comercio e Industria). En este contexto, los periódicos y las revistas especializadas cumplieron una triple función:

Instrumento de divulgación, a gran escala, de los resultados de experiencias -exitosas, o no- sobre cultivo de frutales y sus industrias derivadas en distintos puntos del territorio argentino, mediante informes elaborados por agrónomos. De esta manera, se buscaba, de manera accesoria, motivar a probables interesados para que se volcaran a este tipo de emprendimientos.

Arena de discusión de los problemas y demandas intrínsecos del sector. Este tipo de artículos aparecían de forma esporádica pero en los meses cercanos a la organización de ferias y exposiciones agroindustriales se hacía referencia, regularmente, a las dificultades que atravesaban los fruticultores en Mendoza y en otras regiones. En líneas generales, los tópicos más recurrentes eran las altas tarifas del transporte ferroviario, las dificultades para la comercialización de los productos en el mercado de ventas - desde el punto de vista financiero 
(maniobras especuladoras para la fijación de precios, intermediarios) y técnico (mal estado de la fruta al llegar a destino- y los pedidos para que el Estado promoviera en forma decidida la actividad. Eran recurrentes, asimismo, las referencias a la agroindustria californiana, pues se consideraba el modelo ideal a imitar.

Por último, aunque de una manera incipiente, registramos propagandas para incentivar el consumo de frutas en fresco, asociando el producto a tópicos de salubridad.

Hasta el momento, no hemos podido detectar en el período analizado en Mendoza un boom editorial similar al registrado a principios de siglo $\mathrm{XX}$, cuando varios enólogos $\mathrm{y}$ agrónomos se agruparon para editar publicaciones específicas sobre vitivinicultura y enología, y en menor medida, abordaban algún aspecto de la fruticultura. No obstante, fue importante la participación de técnicos y agrónomos mendocinos -algunos de ellos, miembros de la burocracia técnica- en las mencionadas revistas de circulación nacional; esta dinámica se acentuó notablemente en la década de 1930 a través de la publicación de folletos y boletines agrícolas editados por el Gobierno provincial.

\section{FUENTES}

Boletín de la Sociedad Nacional de Agricultura, Chile, 1924

Boletín del Centro Vitivinícola Nacional. Buenos Aires, 1912

Boletín Mensual del Departamento Nacional de Agricultura, Buenos Aires, 1883

PROVINCIA DE MENDOZA. Boletín Oficial de la Provincia de Mendoza, 1918-1927.

Corporación Frutícola Argentina. Reglamento Interno. 1928.

Diario La Victoria, Mendoza, 1924.

Diario Los Andes, Mendoza, 1923-1928.

GOBIERNO DE LA PROVINCIA DE CÓRDOBA, Primera Conferencia Nacional de Fruticultura, 1926.

GOBIERNO DE LA PROVINCIA DE CÓRDOBA, Segunda Conferencia Nacional de Fruticultura, 1927.

Informe presentado al Ministerio de Agricultura por la Comisión asesora de Estaciones Experimentales y Viveros, Buenos Aires, Imp. Pablo Godola, 1914.

PROVINCIA DE MENDOZA, Recopilación de leyes correspondientes al Ministerio de Industrias y Obras Públicas, T. XI, Mendoza, 1925

Revista de Agricultura, Industria y Comercio. Buenos Aires: Centro Vitivinícola Nacional, 1925-1928 
Revista Comercio e Industria, Mendoza, 1920 y 1924.

Revista Nuestra Tierra. Buenos Aires, 1926-1928

Revista Mensual Buenos Aires al Pacífico, Buenos Aires, 1923-1928.

Videla, R., Exposiciones frutícolas en Cuyo. Su necesidad y manera de realizarlas. Revista mensual B.A.P., n. 64, marzo 1923, p. 21-37.

\section{BIBLIOGRAFÍA}

DI LISCIA, M. S., Y LUCH, A., Argentina en Exposición. Ferias y exhibiciones durante los siglos XIX y XX. Sevilla: Colección Universos Americanos, Consejo Superior de Investigaciones Científicas, 2009.

DJENDEREDJIAN, J. En busca de la excelencia. El impacto de la participación en exposiciones internacionales sobre la producción agropecuaria argentina durante la segunda mitad del siglo XIX. En DI LISCIA, M. S., Y LUCH, A., Argentina en Exposición. Ferias y exhibiciones durante los siglos XIX y XX. Sevilla: Colección Universos Americanos, Consejo Superior de Investigaciones Científicas, 2009.

GIRBAL-BLACHA, N. y OSPITAL, M., Vivir con lo nuestro: Publicidad y política en la Argentina de los años 1930. Revista Europea de Estudios Latinoamericanos y del Caribe, n. 78, abril de 2005, p. 49-65.

GONZÁLEZ STEPHAN, B. Y ANDERMANN, J. (eds), Galerías del progreso. Museos, exposiciones y cultura visual en América Latina. Rosario: Beatriz Viterbo Editora, 2006.

GRACIANO, O. Los caminos de la ciencia. El desarrollo inicial de las Ciencias Agronómica y Veterinarias en Argentina, 1860- 1910, Signos Históricos. U. Autónoma MetropolitanaIztapalapa, n. 12, p. 8-36, 2004.

GUTIÉRREZ, T. Educación, agro y sociedad. Políticas educativas agrarias en la región pampeana. 1870-1955. Bernal: U.N. de Quilmes, 2007

MARTOCCI, F. Enseñar a cultivar en el Territorio pampeano. Escuelas, agronomías y estaciones experimentales (1900-1953). La Pampa: Ediciones INTA- U.N. La Pampa, 2011.

MOYANO, D., CAMPI, D. y LENIS, M. La formación de un complejo científicoexperimental en el norte argentino. La estación experimental agrícola de Tucumán (19091922). Prohistoria [Online]. Rosario, n. 16, 2012. Disponible en http://www.scielo.org.ar/scielo.php?script=sci_arttext\&pid=S1851-

95042011000200002\&lng=es\&nrm=iso\&tlng=es. Fecha de consulta: 10-3-2012.

OSPITAL, M. S., Políticas públicas para la fruticultura en Argentina, 1930-1943. América Latina en la Historia Económica, Instituto Mora, México, n. 1, p. 78-97, 2013. 
WEINBERG, G. La ciencia y la idea de progreso en América Latina, 1860-1930. Buenos Aires: Fondo de Cultura Económica, 1998.

Original recebido em: 01/07/2013

Aceito para a publicação em: 20/07/2013

Resumo do autor:

- Doctora en Ciencias Sociales y Humanas de la Universidad Nacional Quilmes (2011).

- Becaria Posdoctoral de CONICET (2012-2014) con lugar del trabajo en el Instituto de Ciencias Humanas, Sociales y Ambientales (INCIHUSA)-CONICET, dirigida por el Dr. Rodolfo RichardJorba.

- Miembro de proyectos de investigación sobre la conformación histórica de la región vitivinícola argentina, aprobados y financiados por el Consejo Nacional de Investigaciones Científicas y Técnicas (CONICET) y por la Secretaría de Ciencia y Técnica de la Universidad Nacional de Cuyo.

- Sus publicaciones versan sobre el tema de las políticas públicas de enseñanza agrícola y su aporte a la vitivinicultura regional. Entre las más recientes: Educación y vitivinicultura Formación de recursos humanos y generación de conocimientos técnicos en Mendoza (1890-1920), Rosario, Prohistoria, 2012; "Enseñanza agrícola y perspectiva local: la Granja Escuela de San Rafael (1908) como una apuesta al desarrollo micro-regional”, en Sanjurjo de Driollet, Inés (comp.), Pequeños espacios excéntricos. Instituciones, sociedad y economía en la periferia de Mendoza (1900-1955), Prohistoria ediciones (2012); "La Escuela Nacional de Vitivinicultura de Mendoza: la adaptación, generación y difusión de conocimientos aplicados a la industria vitivinícola (1896-1920)”, en Revista de Historia Americana y Argentina, $n^{\circ} 45$ (2011); "La formación de recursos humanos para la vitivinicultura mendocina: desafíos, cambios y continuidades de la enseñanza agrícola en Mendoza, Argentina (1873-1920)”, en Secuencia. Revista de historia y ciencias sociales, nº 84 (2012). 